www.jmscr.igmpublication.org

Impact Factor (SJIF): 6.379

Index Copernicus Value: 79.54

ISSN (e)-2347-176x ISSN (p) 2455-0450

crossrefDOI: https://dx.doi.org/10.18535/jmscr/v6i9.133

Journal Of Medical Science And Clinical Research

IGM Publication

An Official Publication of IGM Publication

\title{
A Case Series of 10 Patients with Trachonychia (20 Nail Dystrophy)
}

\section{Authors \\ Dr Nidhi Paliwal ${ }^{1}$, Dr Kishor Singh ${ }^{2}$}

${ }^{1}$ III $^{\text {rd }}$ year pg resident, Dept. of Dermatology, Venereology \& Leprology (DVL) NIMS Medical College and Hospital, Jaipur

${ }^{2}$ Professor and Head, Dept. of Dermatology, Venereology \& Leprology (DVL), NIMS Medical College and

Hospital, Jaipur

Corresponding Author

Dr Kishor Singh

Professor and Head, Dept. of Dermatology, Venereology \& Leprology (DVL), NIMS Medical College and

Hospital, Jaipur, India

\begin{abstract}
:
Background: Trachyonychia can be a manifestation of a pleomorphic group of disorders or can be idiopathic. The aim of this study to evaluated the clinico-epidemiological characteristics of trachonychia and possible etiologies.

Material \& Methods: All consecutive patients with rough, thinned out nails involving more than five digits, seen over a period of 6 months were included in the study in the department of dermatology \& VD in NIIMS Medical College, Jaipur. Detailed history was taken to find out age of onset and course of nail changes. Patients were clinically evaluated for evidence of any other skin lesions and biopsy was done if any significant skin lesion was found.

Results: The present study included 10 patients, who have average age of onset of disease was $20.1 \pm 14.835$ yrs, clinical presentation was $23.9 \pm 13.295$ yrs and duration of disease was $3.8 \pm 6.364$ yrs. Male to female ratio in our study was 7:3. On clinical examination, 3 patients were found to have skin lesions/mucosal lesions. One patient was found to have erythematous plaques with silvery white scaling over extensor surface of both arms, second patient were found to have violaceous pruritic papules over right leg \& third patient had erosive lesions on the right buccal mucosa with nail dystrophy in 14 nails which on biopsy again confirmed the diagnosis of Lichen Planus. In the remaining 7 patients we could not find the cause for trachyonychia hence we diagnose them as Idiopathic Trachyonychia.

Conclusion: We observed that trachyonychia is a chronic clinical condition that may present as an idiopathic finding or in association with many conditions, especially, psoriasis and lichen planus.

Keywords: Trachyonychia, Skin Biposy, Nail dystrophy, Lichen planus, Psoriasis.
\end{abstract}

\section{Introduction}

Trachyonychia is also known as twenty-nail dystrophy and describes rough, sandpapered nails that are brittle and thin. Trachyonychia was first described by Alkiewicz ${ }^{1}$ in 1950 and was termed twenty-nail dystrophy of childhood in 1977 by Hazelrigg, et $a l^{2}$. This is much more common in children, with an insidious onset and peak age of 3 to 12 years. However, it can occur at any age. 
Trachyonychia can be a manifestation of a pleomorphic group of disorders or can be idiopathic. When associated with alopecia areata, it is more common in male than female patients. This may present as an idiopathic disorder of the nails or it can be associated with other dermatological conditions. ${ }^{3}$

The dystrophic nail findings seen in trachyonychia are characterized by brittle, thin nails \& excessive longitudinal ridging. The nails show diffuse ridging with lack of luster, and in severe cases sandpaper-like surface. The aim of this study to evaluated the clinico- epidemiological characteristics of trachonychia and possible etiologies.

\section{Material \& Methods}

All consecutive patients with rough, thinned out nails involving more than five digits (figure 1), seen over a period of 6 months were included in the study in the department of dermatology \& VD in NIIMS Medical College, Jaipur. All patients underwent $\mathrm{KOH}$ examination and those found positive were excluded from the study.

Detailed history was taken to find out age of onset and course of nail changes. Patients were clinically evaluated for evidence of any other skin lesions and biopsy was done if any significant skin lesion was found.
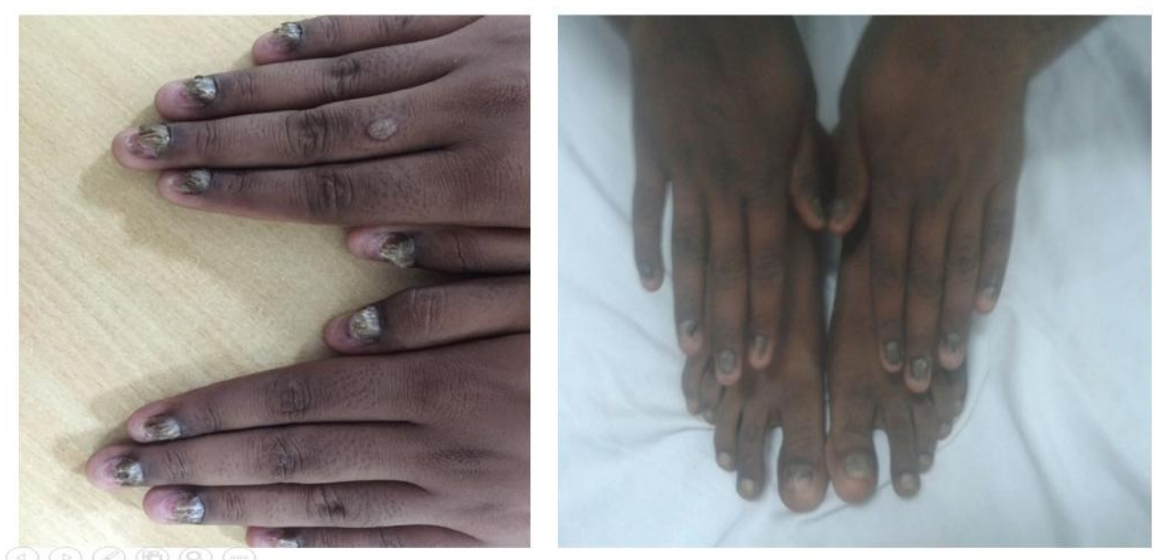

Figure 1: Rough, thinned out nails involving more than five digits

\section{Differential Diagnosis}

As a differential diagnosis to TND, pachyonychia congenita and yellow nail syndrome were considered because of the thickness of the nails. We could, however, not confirm these diagnoses, as we found no mucosal involvement or family history nor any signs of lymphoedema or upper airway problems.

Because of the congenital hip dysplasia, hypermobility and a family history of hypermobility (mother and grandmother), hypermobile Ehlers-Danlos syndrome (EDS) was also considered as a differential diagnosis. The patient did not meet diagnostic criteria and nail abnormalities are not a common finding in EDS.

\section{Results}

The present study included 10 patients, who have average age of onset of disease was $20.1 \pm 14.835$ yrs, clinical presentation was $23.9 \pm 13.295 \mathrm{yrs}$ and duration of disease was $3.8 \pm 6.364$ yrs. Male to female ratio in our study was 7:3 (table 1).

On clinical examination, 3 patients were found to have skin lesions/mucosal lesions. Skin biopsy was taken in all 3 patients to find out the exact etiology behind nail dystrophy.

One patient was found to have erythematous plaques with silvery white scaling over extensor surface of both arms and 20 nail dystrophy. He was clinically diagnosed with Psoriasis and skin biopsy was done which confirmed the diagnosis.

Second patient were found to have violaceous pruritic papules over right leg and dystrophy in all 20 nails. He was diagnosed with Lichen Planus 
clinically. Biopsy from the lesion was done which confirmed the diagnosis.

Third patient had erosive lesions on the right buccal mucosa with nail dystrophy in 14 nails which on biopsy again confirmed the diagnosis of Lichen Planus.

In the remaining 7 patients we could not find the cause for trachyonychia hence we diagnose them as Idiopathic Trachyonychia.

Table 1: Profile of Patients

\begin{tabular}{|l|l|c|}
\hline S.No. & Profile & Observation \\
\hline 1. & Average age of onset & $20.1 \pm 14.835 \mathrm{yrs}$ \\
\hline 2. & Average age of clinical presentation & $23.9 \pm 13.295 \mathrm{yrs}$ \\
\hline 3. & Average duration & $3.8 \pm 6.364 \mathrm{yrs}$ \\
\hline 4. & Average number of nails involved & $14.7 \pm 4.39$ \\
\hline 5. & Male:Female & $7: 3$ \\
\hline 6 & Skin lesion & 3 patients \\
\hline
\end{tabular}

Table 2: Skin biopsy

\begin{tabular}{|l|c|c|c|c|c|c|}
\hline $\begin{array}{l}\text { No. } \\
\text { patients }\end{array}$ & Diagnosis & $\begin{array}{c}\text { No. Of Nails } \\
\text { involved }\end{array}$ & Type of skin lesion & Site & $\begin{array}{c}\text { Skin } \\
\text { Biopsy }\end{array}$ & $\begin{array}{c}\text { Nail } \\
\text { Biopsy }\end{array}$ \\
\hline 1 & Psoriasis & 20 & $\begin{array}{c}\text { Erythematous } \\
\text { plaques with silver } \\
\text { scaling }\end{array}$ & $\begin{array}{c}\text { Extensor } \\
\text { surface of both } \\
\text { arms }\end{array}$ & + & - \\
\hline 1 & $\begin{array}{c}\text { Lichen } \\
\text { planus }\end{array}$ & 20 & $\begin{array}{c}\text { Violaceous pruritic } \\
\text { plaques }\end{array}$ & $\begin{array}{c}\text { Extensor aspect } \\
\text { of right leg }\end{array}$ & + & - \\
\hline 1 & $\begin{array}{c}\text { Oral Lichen } \\
\text { planus }\end{array}$ & 14 & Erosive lesions & $\begin{array}{c}\text { Right buccal } \\
\text { mucosa }\end{array}$ & + & - \\
\hline 7 & Idiopathic & $\geq 5$ & - & - & - & - \\
\hline
\end{tabular}

\section{Discussion}

Most cases of TND are considered idiopathic. However, a few case reports have shown possible association between TND and other concomitant dermatoses and other comorbidities such as eczema, psoriasis, lichen planus, vitiligo and alopecia areata. ${ }^{4,5}$

Depending on the severity, it is possibile to distinguish two clinical varieties of trachyonychia: a severe type, characterized by opaque, sandpaper nails, and a mild type characterized by shiny nails with superficial ridging and diffuse pitting. Koilonychia can be seen in both types.

The extent of inflammation in the nail matrix is thought to contribute to the wide range of severity observed in trachyonychia. Tosti et al. ${ }^{6}$ have hypothesized that when inflammation is severe and persistent, diffuse damage causes an opaque variety. In contrast, mild and intermittent inflammation results in multifocal damage, with nails that retain their luster as a result. ${ }^{7}$ This hypothesis is supported by the variable location of histopathologic changes observed in trachyonychia, which are more prominent in the proximal nail matrix and ventral proximal nail fold; this non uniform inflammatory activity results in a spectrum of disease severity. ${ }^{8}$

The risk/benefit ratio of performing a nail biopsy to identify the pathological cause of trachyonychia dictates that a nail matrix biopsy should not be a part of standard procedure. Pathological studies of trachyonychia showed that the most common features are spongiosis and exocytosis of inflammatory cells into the nail epithelia. ${ }^{6,9-11}$ Histopathology can also show the features of nail matrix lichen planus or nail matrix psoriasis. Further, trachyonychia due to nail lichen planus has been reported to occur in patients with alopecia $\operatorname{areata}^{12}$, suggesting that these two diseases can occur simultaneously. ${ }^{8}$

\section{Conclusion}

Trachyonychia is a chronic clinical condition that may present as an idiopathic finding or in association with many conditions, especially, psoriasis and lichen planus. While the 
histopathological findings have been well documented, the diagnosis of trachyonychia can most often be made based on the distinguishing clinical symptoms.

\section{References}

1. Alkiewicz J. Trachyonychia. Ann Dermatol Syphiligr (Paris) 1950;10:136140.

2. Hazelrigg DE, Duncan WC, Jarratt M. Twenty-nail dystrophy of childhood. Arch Dermatol. 1977;113:73-75.

3. Baran R, Dawber R. Twenty-nail dystrophy of childhood: a misnamed syndrome. Cutis. 1987;39:481-482.

4. Lee YB, Cheon MS, Park HJ et al. Clinical study of twenty-nail dystrophy in Korea. Int J Dermatol2012;51:677-81.

5. Holzberg M. Common nail disorders. Dermatol Clin 2006;24:349-54.

6. Tosti A, Bardazzi F, Piraccini BM, Fanti PA. Idiopathic trachyonychia (twenty-nail dystrophy): a pathological study of 23 patients. Br J Dermatol. 1994;131:866872.

7. Tosti A, Piraccini BM, Iorizzo M. Trachyonychia and related disorders: evaluation and treatment plans. Dermatol Ther. 2002;15:121-125.

8. Gordon KA, Vega JM, Tosti A. Trachyonychia: a comprehensive review. Indian J Dermatol Venereol Leprol. 2011;77:640-645.

9. Tosti A, Fanti PA, Morelli R, Bardazzi F. Trachyonychia associated with alopecia areata: a clinical and pathologic study. J Am Acad Dermatol. 1991;25:266-270.

10. Grover C, Khandpur S, Reddy BS, Chaturvedi KU. Longitudinal nail biopsy: utility in 20-nail dystrophy. Dermatol Surg. 2003;29:1125-1129.
11. Jerasutus

$\mathrm{S}$,

Suvanprakorn $\mathrm{P}$, Kitchawengkul O. Twenty-nail dystrophy. A clinical manifestation of spongiotic inflammation of the nail matrix. Arch Dermatol. 1990;126:1068-1070.

12. Kanwar AJ, Ghosh S, Thami GP, Kaur S. Twenty-nail dystrophy due to lichen planus in a patient with alopecia areata. Clin Experiment Dermatol 1993;18:293-294. 